\title{
A Parametric Thermal Analysis of Triangular Fins for Improved Heat Transfer in Forced Convection
}

\author{
Saroj Yadav - Krishna Murari Pandey* \\ National Institute of Technology Silchar, India
}

Thermal management systems in electronic devices require a reduction in size due to improve the overall performance of the system. The aim is to improve the heat transfer with reduction in weight of the system. Fins are the extended surfaces that ease the heat transfer process by increasing the wetted surface area. The thermal diffusion in a fin is always affected by parameters like the size, the shape, the material, the relative arrangement, orientation and position of the fins, the working fluid and its velocity, etc. Moreover, an extended surface may affect the pressure gradient in the flow domain. In this article, a three dimensional (3D) system of aluminium fin system has been numerically modelled. Simulations are done for conjugate heat transfer problem with fins of triangular shape. The thermal analysis is performed for various input parameters viz., arrangements, orientation and the number of fins. The effect of these parameters are analysed based on Nusselt number, convective heat transfer coefficient, coefficient of friction and coefficient of pressure.

Keywords: conjugate heat transfer, extended surfaces, finite element method, heat transfer co-efficient, Nusselt number, triangular fins

Highlights

- The extended surface improves the heat transfer rate in any system by improving the thermal interaction between the solid surface and the fluid.

- Heat transfer rate in a fin is always affected by the size, the shape, the material, the relative arrangement, the orientation and position of the fins, the working fluid and its velocity, etc.

- $\quad$ Presence of an extended surface affects the pressure gradient in the flow domain.

- Variation of Nusselt number, frictional coefficient, pressure coefficient and heat transfer co-efficient are affected by the arrangement, orientation and the number of fins.

\section{INTRODUCTION}

Any system is under working condition generates heat. Sometimes, the amount of heat that it generates reaches the threshold limit of the system. Therefore, in order to avoid the damaging of the components of the system due to burning or overheating, it is very important to remove the heat in an effective way. Thus, heat transfer in enhanced rate is one of the important topics of thermal engineering. Enhancing the heat transfer rate with the controlled system dimension in the equipment like electronics, heat exchangers, aeronautical, internal combustion engine, etc. have always been a challenging task. To conquer this, researchers are continuously giving their effort in designing or reconstructing a new device with high thermal performance. These devices are intended for cost-effective and energy efficient transfer of heat in the compact areas without any thermodynamic loss. In this concern, an array of fins is one of the possible ways to increase the heat transfer rate from the base surfaces. This method can increase the heat transfer area that comes in contact with the fluid. Fin geometries and fin arrays can create turbulence in the fluid flowing, this further increase the heat transfer coefficient $(h)$ between systems and surrounding and thus improve the performance. However, it gives rise to the pressure drop, which is a critical condition in most high performance applications. Consequently, it can be said that an optimized fin geometry and fin array combination is a conciliation of performance, pressure drop, weight, and size.

The fin materials usually have a high thermal conductivity, thus it conducts the heat from the wall in high rate. Mostly, fins are used to enhance convective heat transfer by creating the temperature difference between the object and the environment. This in turn increases the convection heat transfer coefficient. Pin fin heat sinks are one of the competent heat exchanging devices used in many electric cooling appliances including central processing unit (CPU), transformer and thyristor. Thus most of the high thermal performance application based fins are made of copper or aluminium. Aluminium is always a preferred material for fins used in electronic system for cooling applications, due to its higher thermal conductivity and light weight.

Researcher proposed many techniques through experimental, analytical and numerical analysis for the performance augmentation of extended surfaces, specifically pin fin heat exchanger. Pin-fin arrays induced turbulence in the flow field which further 
helpful in enhancement of heat transfer. Axtmann et al. [1] focused their studies on thermally inactive pinfins and presented the heat transfer results in terms of Nusselt number $(\mathrm{Nu})$ and also discussed about other individualities like pressure drop and thermal performance parameter of investigated configurations. Şara [2], experimentally investigated the heat transfer, pressure and performing individualities for the array of staggered square pin fins attached on a flat surface in a rectangular duct and compared it with those for the inline arrangement. Jeng and Tzeng [3] also explore the heat transfer and the pressure drop in square pinfins with variable inter-fin pitches for understandings of pin-fin arrays and systematic experiments has been performed, consequently the optimal inter-fin pitches are provided. Metzger et al. [4] presented variation in stream wise heat transfer, overall array heat transfer, and overall flow friction behavior for large aspect ratio ducts, that contained uniformly spaced staggered arrays of circular pin fins. Agarwal et al. [5] explored the effectiveness of pin fins for heat transfer in a channel cooled by air and agitated by a translational oscillating plate. Park et al. [6] designed a staggered pin-fin radial heat sink. The system was optimized for cooling of light-emitting diode (LED) device. They developed a numerical model to simulate various pin-fin array heat sinks. The results were verified experimentally. Huang et al. [7] estimated the optimal diameters for perforated pin fin array based on the desired temperature difference between base plate averaged temperature and ambient temperature and system pressure drop. The heat transfer and friction factor characteristics of the perforated rectangular fins were determined by Sahin and Demir [8]. The performances of three dimensional (3D) conjugate thermo-fluid analysis of micro pin-fins were presented by Abdoli et al. [9]. They considered a conventional circular shape, a hydrofoil shape, a modified hydrofoil shape and a symmetric convex lens shape of a fin. Joo and Kim [10] presented an analytical comparison of the thermal performances of optimized plate-fin and optimized pin-fin heat sinks under fixed volume condition. McNeil et al. [11] measured the heattransfer coefficient and pressure drop measurements for a heat sink comprising micro pin-fins.

In the following, a study has been performed on triangular fins with different geometrical parameters. The solver and the developed model are validated with the experimental data and with empirical relations available in the literature. Further, the variation of $\mathrm{Nu}, h$, coefficient of friction $\left(C_{f}\right)$ and coefficient of pressure $\left(C_{p}\right)$ are studied by varying the arrangement, orientation and the number of fins.

\section{FORMULATIONS AND GEOMETRY}

Thermal analyses of extended surfaces of different shapes are performed in this article.

\subsection{Experimental Set-Up}

Experiments are carried out to understand the performance of a set of aluminium pipe bundle arranged in a staggered manner. Fig. 1a shows the experimental set-up used in the current study. The set-up consists of a vertical square duct with an axial flow fan placed just below the outlet temperature sensor. Air enters the duct from the bottom and leaves it from the top. The staggered arrangement of the pin fin system with the base plate as shown in Fig. 1b. The fins with the base plate are connected with the heater unit to supply heat from the bottom of the plate (Fig. 1b). The removable set-up (Fig. 1b) of fins with heating unit is placed inside the duct in the test section. The placement of the fins in the test section provides normal direction of flow to the incoming fluid (Fig. 1a). Fixed temperature sensors are provided

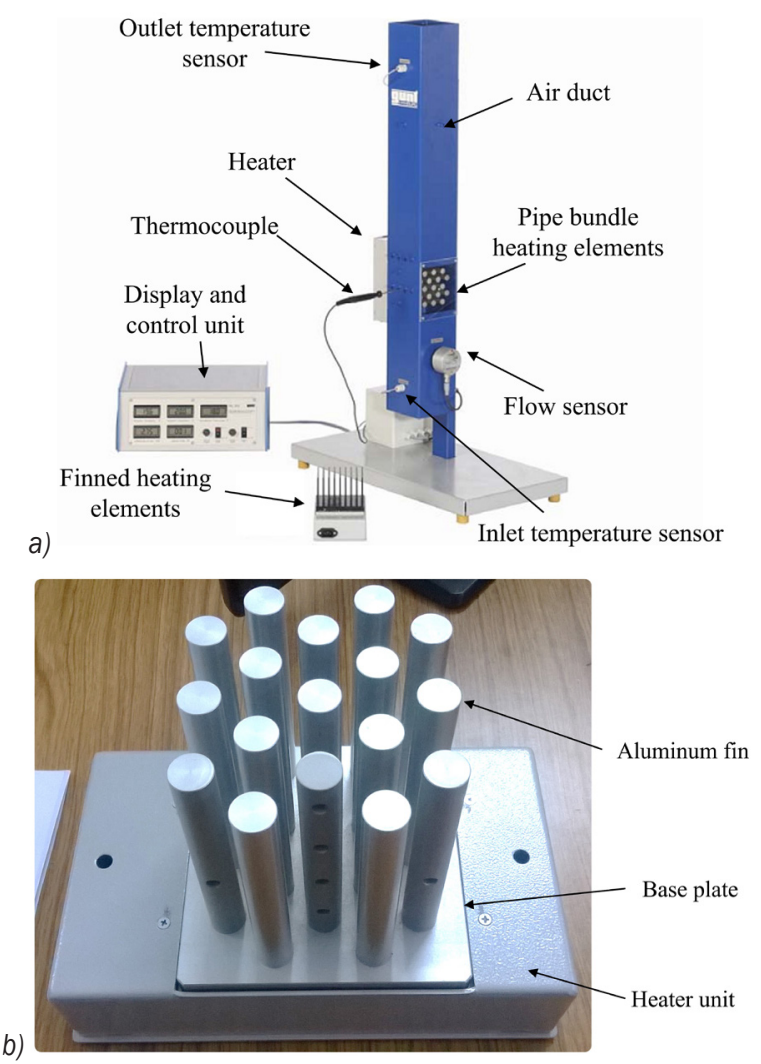

Fig. 1. The experimental setup of a) heat convection apparatus, and b) pipe bundle heating element 
at the inlet and the outlet of the duct to measure the temperatures of incoming and outgoing air, respectively. A portable thermocouple is also provided to measure the temperature at different locations of the fins. The display and control unit helps in controlling the speed of the fan and the amount of supplied heat to the heating unit.

\subsection{Computational Model}

Consideration is given to a 3D numerical model of aluminum pipe bundle placed in an air duct of dimension $L \times H \times L$ (Fig. 2a). The fins of diameter $D$ and height $l$, arranged in a staggered formation are placed over a base plate of dimension $L_{b} \times L_{b} \times H_{b}$ (Fig. $2 b)$. The arrangement is located inside the air duct at a distance $\left(H-L_{b}\right) / 2$ from the inlet. With a longitudinal and transverse pitch of $S_{L}$ and $S_{T}$, the system is analyzed for a forced convection scenario. The considered numerical model is validated prior to the analysis of different cases. Air is driven inside the duct at an isothermal room temperature $T_{f}$ and velocity $V$ in the positive $y$ direction. Numerically, the outlet is considered to be at atmospheric pressure $\left(P_{o}\right)$ and at outflow condition $(\hat{n} \cdot \nabla T=0)$. The walls of the air duct are at no slip conditions $(|\vec{V}|=0)$ and at an isothermal room temperature $T_{f}$ (Fig. 2a). The base plate of the fin system is supplied with a total uniform heat of $Q_{s}$.

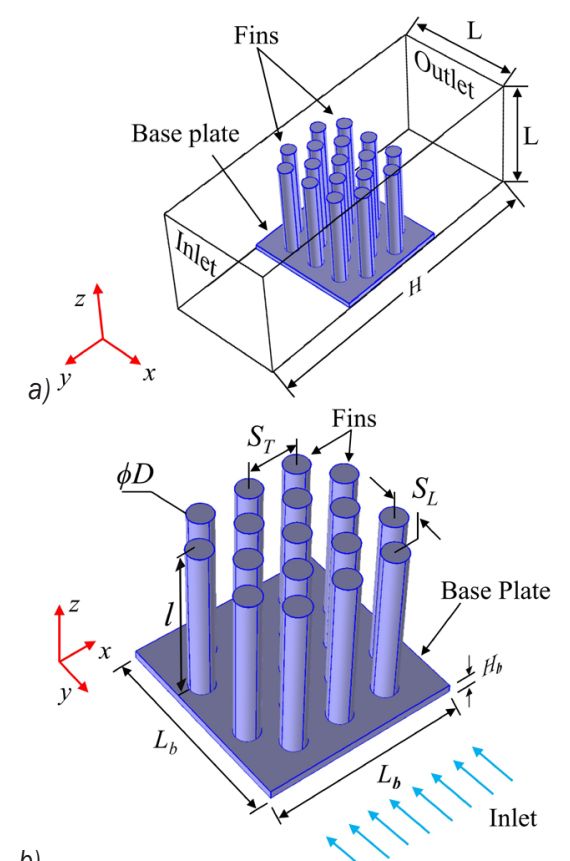

Fig. 2. Schematic diagram of the a) computational domain, and b) fin geometry

\subsection{Governing Equations}

Thermal behavior of any system is determined by the participated modes of heat transfer, and the thermo physical properties of the system.

\subsubsection{Experimental Analysis}

In this study, the experimental analysis has been performed considering the force convection over the fin surfaces. The system is analysed based on the performance parameters like $h$ and averaged $\mathrm{Nu}$. The facility helps in measurement of various thermo physical properties of the system like system dimensions, the velocity and the temperature at various points. These quantities forms the basis for calculation of $h$ and $\mathrm{Nu}$ in the system. For the current system (Fig. 1a), at various inlet flow velocities, with known values of temperature at inlet, outlet and over the fins, the $h$ is calculated from the thermal energy balance. In ideal scenario, neglecting any heat loss from the back of the heater and from the duct walls (Fig. 1a), the rate of heat convection from the surface of the fin will be equal to the rate of heat carried by the incoming air. Mathematically, it can be expressed as,

$$
h A_{\text {fin }}\left(T_{\text {fin }}-T_{\text {in }}\right)=\dot{m} c_{p}\left(T_{\text {out }}-T_{\text {in }}\right),
$$

where the $A_{f i n}$ is the wetted surface area of the fin, the $T_{\text {fin }}$ is the average surface temperature and $\dot{m}\left(=\rho A_{\text {duct }} V\right)$ is the mass flow rate inside the duct. Considering diameter $D$ of the fin as the characteristic length, the average $\mathrm{Nu}$ is calculated using $h L / k_{f}$.

\subsubsection{Uncertainty in Experimental Data}

Every experiment needs analysis of uncertainty in the measured quantities. The uncertainty in the dependent derived quantities are due to various errors that appear in the measured quantities. In the present case, the uncertainty in the measurement of $h$ and $\mathrm{Nu}$ are calculated using root mean square combination Eq. (2). In general, for any quantity $\lambda$, it is expressed as

$$
E_{\lambda}=\sqrt{\sum_{i=1}^{N}\left(\frac{\partial \lambda}{\partial x_{i}} E_{i}\right)^{2}},
$$

where $E_{i}$ is the uncertainty in the generic variable $x_{i}$. In the calculations of uncertainty of $h$, the generic variables are various areas, $A_{\text {duct }}$ and $A_{\text {fin }}$, velocity $V$, and temperatures $T_{\text {in }}, T_{\text {out }}$ and $T_{\text {fin }}$. Similarly, for $\mathrm{Nu}$, it will be $h$ and $D$. 


\subsubsection{Numerical Analysis}

The numerical study of the fin geometry requires combination of multiple physics of heat transfer and fluid flow to capture variation of temperature, velocity and pressure field in the domain (Fig. 2a). Considering forced convection over the present system, the conjugate heat transfer energy equation is expressed as,

$$
\rho c_{p}\left(\frac{\partial T}{\partial t}+\vec{V} \cdot \nabla T\right)=\nabla \cdot(k \nabla T),
$$

where $\rho, c_{p}$ and $k$ are the density, the specific heat and thermal conductivity of the materials of the system. The $\nabla$ is the gradient operator. In the above equation, the first and the second terms are the rate of accumulation of thermal energy and the rate of transfer of thermal energy due to bulk motion of the fluid, respectively. The term on the right hand side corresponds to the rate of thermal diffusion in the material.

With the known value of thermal properties, evaluation of temperature field of the system from Eq. (3) requires the knowledge of the velocity field. Therefore, apart from the energy equation, the governing equations of the considered system (Fig. 1a) also include steady form of continuity and momentum equations, given by

$$
\begin{gathered}
\nabla \cdot(\rho \vec{V})=0, \\
\vec{V} \cdot \nabla \vec{V}=-\frac{1}{\rho} \nabla p+v \nabla^{2} \vec{V} .
\end{gathered}
$$

The governing equation Eqs. (3) to (5) has been solved numerically using finite element method (FEM). The discretization is performed using COMSOL multiphysics, a commercially available FEM solver. Simultaneous solution of Eqs. (3) to (5), using the mentioned boundary conditions yields the velocity and the temperature profiles in the computational domain. The average $\mathrm{Nu}$ and $h$ in such cases are calculated using

$$
\mathrm{Nu}=\frac{Q_{S} D}{k_{f} A\left(T_{w}-T_{f}\right)}=\frac{h D}{k_{f}},
$$

where $A$ and $T_{w}$ are the area of the base plate $\left(L_{b} \times L_{b}\right)$ and the average surface temperature of the fin walls, respectively.

The skin friction and the pressure coefficients are two non-dimensional quantities that gives an overview how the flow is interacted with the contact surface. Mathematically,

$$
\begin{aligned}
& C_{f}=\frac{2 \tau_{w}}{\rho V^{2}}, \\
& C_{p}=\frac{2 \Delta P}{\rho V^{2}},
\end{aligned}
$$

where $\tau_{w}$ and $\Delta P$ are local wall shear stress $\left[\mathrm{N} / \mathrm{m}^{2}\right]$ and pressure difference $\left[\mathrm{N} / \mathrm{m}^{2}\right]$ respectively.

\subsubsection{Empirical Relations}

Fluid flow across a heated cylindrical pin fin is a common problem in various engineering applications. One such work has been carried out by Khan et al. [12]. The authors in this work have discussed on cylindrical pin fin heat sink with application in electronic thermal management system. Khan et al. [12] have proposed mathematical relationships $h$ for fin with various physical parameters of fin geometry. For any pipe bundle arrangement, with an approaching fluid velocity of $U=|\vec{V}|$ the Reynolds number (Re) for the flow is defined as

$$
\operatorname{Re}_{D}=\frac{v U_{\max }}{D}
$$

where $v$ is the kinematic viscosity of the flowing fluid and $U_{\max }$ is the maximum fluid velocity around the fins. As proposed by Khan et al. [12], the $U_{\max }$ is obtained from the empirical relation given by

$$
U_{\max }=\max \left(\frac{S_{T}}{S_{T}-D} U, \frac{S_{T}}{2\left(S_{D}-D\right)} U\right)
$$

where $S_{D}=\sqrt{S_{L}^{2}+\left(S_{T} / 2\right)^{2}}$ is the diagonal pitch in the present case. Using these physical parameters of the system, the average $\mathrm{Nu}$ for the staggered arrangement fins is expressed in terms of $\mathrm{Re}$ and Prandtl number $(\mathrm{Pr})$ as

$$
\mathrm{Nu}=\frac{h D}{k_{f}}=C_{1} \operatorname{Re}_{D}^{1 / 2} \operatorname{Pr}^{1 / 3},
$$

where $C_{1}=\frac{0.61 S_{T}^{0.091} S_{L}^{0.053}}{1-2 e^{-1.09 S_{L}}}[12]$.

For a cylindrical pin fin geometry, considering the results obtained from the experiments, the numerical model is validated. The set of results are also compared with the values of $\mathrm{Nu}$ and $h$ obtained from the above mentioned empirical relations [12].

\section{RESULTS AND DISCUSSION}

The considered numerical model has been developed based on the available experimental set-up (Fig. 2 ). In order to compare the results of numerical solver with experiment, the boundary conditions are 
carefully chosen to simulate the realistic scenario of experiments. Consideration is given to 17 number of Aluminum $k=237 \mathrm{~W} /(\mathrm{m} \cdot \mathrm{K}), \quad \rho=2700 \mathrm{~kg} / \mathrm{m}^{3}$, $C_{p}=900 \mathrm{~J} /(\mathrm{kg} \cdot \mathrm{K})$, cylindrical pin fins $(D=15 \mathrm{~mm}$, $l=105 \mathrm{~mm})$ placed over a base plate of dimension $\left(L_{b} \times L_{b} \times H_{b}\right) \quad 118 \mathrm{~mm} \times 118 \mathrm{~mm} \times 5 \mathrm{~mm}$. The fins are arranged in 3 rows of 3 fins and 2 rows of 4 fins (Fig. 2b). The arrangement is placed inside square duct of dimension $(L \times H \times L) 120 \mathrm{~mm} \times 120 \mathrm{~mm} \times$ $628 \mathrm{~mm}$ (Fig. 2a). In the numerical model, the height $(H)$ of the square duct is kept as $628 \mathrm{~mm}$ instead of $1000 \mathrm{~mm}$ of the actual experimental set-up. The consideration has been made in order to reduce the size of the computational domain and to nullify the effect of the outlet conditions. During the experiment, the fin geometry along with the base plate is subjected to a total heat of $115 \mathrm{~W}$, normal to the bottom of the base plate. The experiments are performed at five different ambient conditions. The results are noted down at steady state condition of the system. In order to check the repeatability of the measurement systems, four readings are recorded corresponding to a single setting of the process parameters. Uncertainty in the estimation of $\mathrm{Nu}$ and $h$ are also shown while comparing with numerical and empirical results.

The $\mathrm{Nu}$ is a parameter that depicts the strength of the convection heat transfer rate compared to the conductive heat transfer rate. The performance parameters $(\mathrm{Nu}$ and $h)$ in the considered system are calculated using the experimental data (Eq. (1)), empirical relations Eqs. (9) to (11) and computationally (Eq. 6). The empirical relationships proposed by Khan et al. [12] are applicable for a staggered arrangement of cylindrical pin fin, which are independent of the boundary conditions. With longitudinal and transverse pitch of $\left(S_{L}\right) 20 \mathrm{~mm}$ and $\left(S_{T}\right) 30 \mathrm{~mm}$, respectively the $\mathrm{Nu}$ and $h$ are calculated using the given relations (Eqs. (9) to (11)). The Re and Pr are the flow dependent parameters that can be calculated using the maximum velocity $U_{\max }$ and other fluid properties. For all the above study, the $\mathrm{Nu}$ and $h$ is calculated based on the diameter $D$ of the fins.

With tetrahedral grid to discretize the computational domain, the grid dependency tests were performed for different sizes of the grid. Using a grid having 15,84,685 numbers of elements, the governing equations were solved for a steady-state condition. Five cases are taken into considerations for various inlet velocities of air viz., $1.1 \mathrm{~m} / \mathrm{s}, 1.3 \mathrm{~m} / \mathrm{s}, 1.5$ $\mathrm{m} / \mathrm{s}, 1.8 \mathrm{~m} / \mathrm{s}$ and $2.0 \mathrm{~m} / \mathrm{s}$. Table 1 shows comparative values of average $\mathrm{Nu}$ and $h$ for different cases of inlet velocities. A comparative plot of the same is also presented in Fig. 3.
Having validated the numerical solver, the fins of triangular shape are considered for study. The fins are modeled in such a way that the volume of the system is always maintained constant $\left(229 \mathrm{~mm}^{3}\right)$. For the study of effect of number of fins, in order to maintain uniformity in the modeling, the heights to base ratio of the fins are always kept same for all the cases, i.e., 2.5.

Table 1. Comparison of empirical and numerically obtained $\mathrm{Nu}$ and $h$ for various conditions of Inlet velocity and temperature

\begin{tabular}{|c|c|c|c|c|c|c|c|c|c|c|}
\hline \multirow[b]{2}{*}{$V$} & \multirow[b]{2}{*}{ 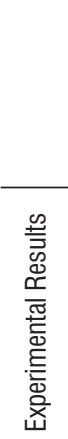 } & \multicolumn{2}{|l|}{$\mathrm{Nu}$} & \multicolumn{3}{|c|}{$h\left[\mathrm{~W} /\left(\mathrm{m}^{2} \cdot \mathrm{K}\right)\right]$} & \multicolumn{2}{|c|}{$\begin{array}{l}\% \text { Error in } \\
\text { estimation } \\
\text { of } \\
\text { Numerical } \\
\text { Nu with }\end{array}$} & \multicolumn{2}{|c|}{$\begin{array}{c}\% \text { Error in } \\
\text { estimation } \\
\text { of } \\
\text { Numerical } \\
\mathrm{h} \text { with }\end{array}$} \\
\hline & & 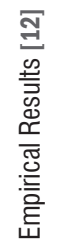 & 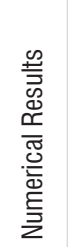 & 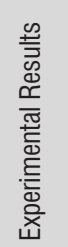 & 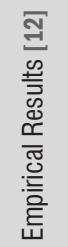 & 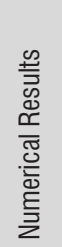 & 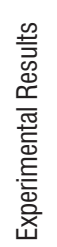 & 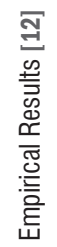 & 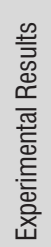 & 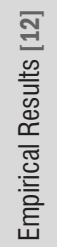 \\
\hline 1.1 & 27.9 & 29.0 & 26.8 & 48.8 & 50.7 & 45.9 & 4.1 & 8.2 & 6.3 & 10.5 \\
\hline 1.3 & 30.4 & 31.5 & 32.7 & 53.1 & 55.1 & 56.1 & 7.2 & 3.8 & 5.3 & 1.8 \\
\hline 1.5 & 33.0 & 33.8 & 34.4 & 57.6 & 59.1 & 58.9 & 4.1 & 1.7 & 2.2 & 0.3 \\
\hline 1.8 & 38.6 & 37.1 & 36.2 & 67.5 & 64.8 & 62.0 & 6.6 & 2.5 & 8.8 & 4.5 \\
\hline 2.0 & 42.2 & 40.0 & 42.3 & 73.7 & 70.0 & 72.4 & 0.2 & 5.4 & 1.8 & 3.4 \\
\hline
\end{tabular}

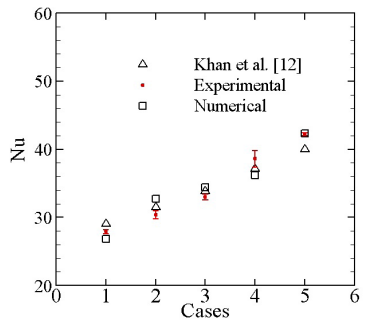

a)

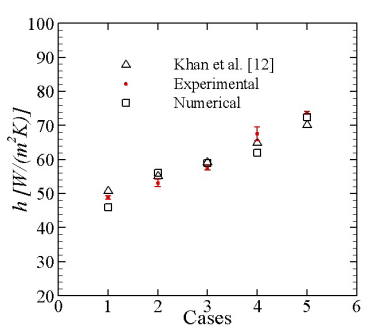

b)
Fig. 3. Comparison of numerical, experimental and empirical values of: a) $\mathrm{Nu}$ and b) $h$

\subsection{Inline vs. Staggered Arrangement}

The relative position of the fins plays an important role in the heat transfer process. In this study, the thermal analysis is performed on a 2-2 inline and 2-12 staggered arrangement of fins as described in (Fig. $4)$. The base $(b)$ and the altitude $(a)$ of the fin are selected in a way to accommodate the fin-base plate assembly in a space of $13 \times 13 \mathrm{~mm}^{2}$. For the inline arrangement of the fins, the base $(b)$ and the altitude (a) is taken as $4.9857 \mathrm{~mm}$ and $10 \mathrm{~mm}$, respectively.

As the number of fins in the considered staggered arrangement is more than that of the inline 
arrangement, the base and altitude of the fins in this case will reduce to $3.989 \mathrm{~mm}$ and $10 \mathrm{~mm}$ to maintain a total volume of $229 \mathrm{~mm}^{3}$. The thicknesses of the fins are also maintained at a constant value of 0.6 $\mathrm{mm}$, throughout the study. The set of fins are placed over a baseplate of $1 \mathrm{~mm}$ thickness with the trailing edge located at $y=0$. The system is supplied with a total uniform heat $\left(Q_{s}\right)$ of $2 \mathrm{~W}$ from the base of the base plate. A unidirectional flow of air is imposed as the inlet condition with velocity of $0.5 \mathrm{~m} / \mathrm{s}$. Fig. 5a and $b$ show the results obtained from the numerical simulations. The stream line of velocity plot in a horizontal section $(z=6 \mathrm{~mm})$ shows the flow over the considered extended surfaces. In the staggered arrangement, the interaction between the solid and air is observed to be more compared to the inline arrangement. It is due to the placement of the fifth fin between two rows in the staggered arrangement. The contours in the Fig. 5 shows variation of temperature at the horizontal middle plane $(z=6 \mathrm{~mm})$ of the rectangular domain.

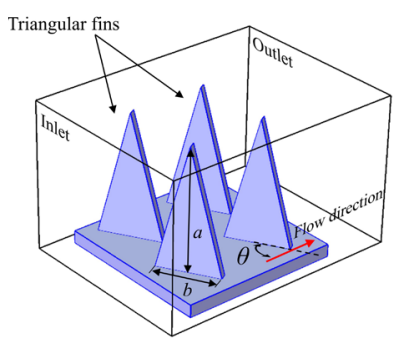

a)

Fig. 4. Schematic diagram of a) inline, and b) staggered arrangement of triangular fins

a)

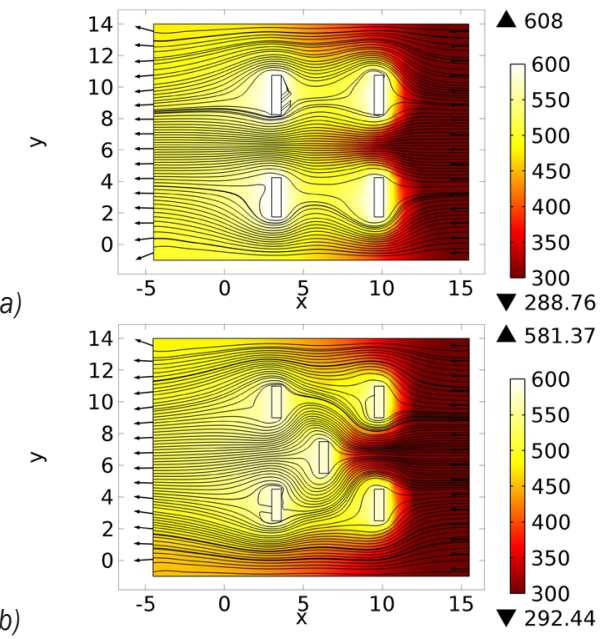

Fig. 5. Velocity streamline, direction and surface temperature $[K]$ variation in: a) inline, and b) staggered arrangement of fins in a plane at $z=6 \mathrm{~mm}$
Following the formulations in the previous section, the values of $h$ and the $\mathrm{Nu}$ is calculated for the considered inline and staggered arrangement. For the staggered arrangement of triangular fins, $h$ is observed to be $44.14 \mathrm{~W} /\left(\mathrm{m}^{2} \cdot \mathrm{K}\right)$, which is $22 \%$ higher than the value in case of inline arrangement, i.e., $34.46 \mathrm{~W} /\left(\mathrm{m}^{2} \cdot \mathrm{K}\right)$. The observed increment in $h$ is due to a better interaction at the fluid-solid interface. The increased number of fins in this case also helped in increasing the total wetted surface area of the fin by $2.56 \%$, which in turn enhances the heat transfer rate. Hence, there is an increment in the $\mathrm{Nu}$ too. The $\mathrm{Nu}$ value increases from 1.18 to 1.46 in case of staggered arrangement compared to inline arrangement.

The presence of the fins inside the rectangular duct induces a circulation in the flow. The same is realized from the variation of $y$-component of velocity (Fig. 6), immediately after the flow passes over the fins (at $x=0$ ). The clockwise and the counterclockwise vortices formed due to the fin structure shows more prominent presence near the left and the right wall of the duct, respectively, for both arrangements. Therefore, the air near these boundaries have almost equal thermal interaction and heat dissipation near the walls as that of the core (Fig. 6). With an improved rate of heat transfer in staggered arrangement in triangular fins, next the study has been extended to understand the flow losses with the help of $C_{f}$ and $C_{p}$. Upon comparison, it has been found that the inline arrangement of fins yield a higher value of $C_{f}$ and $C_{p}$ than the staggered arrangement of the fins. A staggered arrangement of the fins with equivalent inline arrangement, having same material volume show $C_{f}=0.0678$ and $C_{p}=9.325$. On the other hand, the same quantities for inline arrangement have been obtained as 0.08716 and 9.67, respectively. Although the dimensions of the fins in both the arrangements are opted in a way to maintain a uniform volume, however, the wetted surface area obtained for both the cases are found different. In the inline arrangement of the fin system, four fins along with the base plate are having total approximate wetted surface area of $398 \mathrm{~mm}^{2}$. On the other hand, the system of fins in the staggered arrangement consists of $361 \mathrm{~mm}^{2}$. The reduced wetted surface area in the staggered arrangement leads to lesser frictional losses in the flow system. Therefore, in comparison to inline arrangement, the staggered arrangement of the fins yields $22 \%$ and $3 \%$ reduction in the value of $C_{f}$ and $C_{p}$, respectively. Therefore, a staggered arrangement always results in higher value of heat transfer rate with minimum flow losses, over the inline arrangement. 

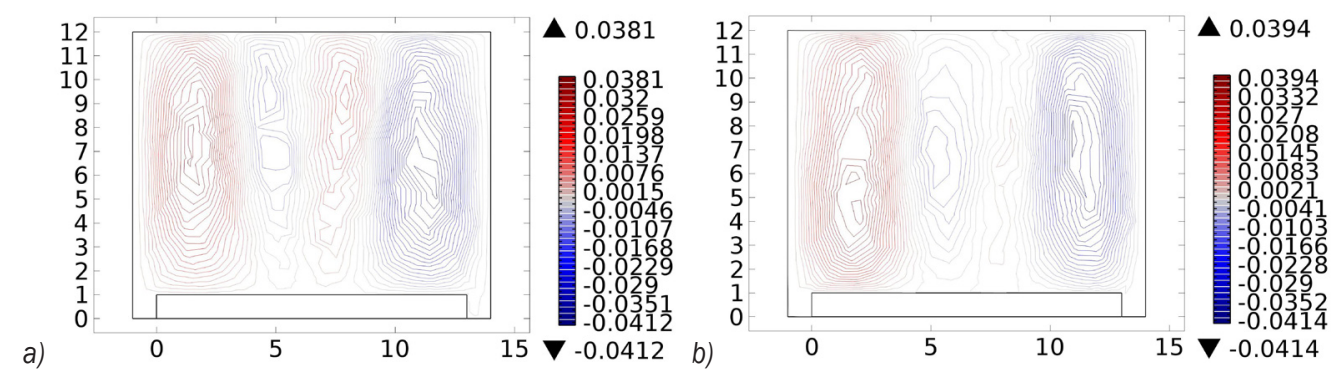

Fig. 6. Contour profile of $y$-component of velocity $(v,[\mathrm{~m} / \mathrm{s}])$ in a) inline, and $b)$ staggered arrangement of fins in a plane at $x=0$

\subsection{Relative Orientation of the Fins}

Presence of an extended surface contributes in the pressure drop along the flow direction. In this regard, the orientation of the surfaces plays a major role. The current study focuses on the study of relative orientation of the fins with flow direction on heat transfer and fluid flow. Considering five variation of angles viz., $0^{\circ}, 30^{\circ}, 45^{\circ}, 60^{\circ}$ and $90^{\circ}$, thermal analysis is made on triangular fins under same thermal load and boundary conditions.

Fig. 7 shows the surface temperature contour and the velocity streamlines at $z=6 \mathrm{~mm}$ for all the considered cases. In case of triangular fins with $\theta=0^{\circ}$, the temperature contour shows a better distribution of temperature of air throughout the computational domain. However, due to angular orientation of the fins the flow is diverted towards one of the boundary which is parallel to the horizontal axis. Therefore, in case $30^{\circ}, 45^{\circ}$ and $60^{\circ}$, the temperature contour and the streamlines are observed to deviate towards the flow direction. In case with $\theta=90^{\circ}$, for the fluid moving normal to the triangular face of the fins, the fluid particles reaches a stagnation condition and imposes pressure on the fin wall (Fig. $8)$. The situation is less prominent as one move from $90^{\circ}$ through $0^{\circ}$.

Therefore, due to symmetric flow of air, in case of $\theta=0^{\circ}$, with better thermal interaction, a better heat transfer phenomenon is observed. The same may be realized from the calculation of $\mathrm{Nu}$ and $h$. Fig. 9 shows a comparative bar diagram of all the above cases. For the fins with triangular faces parallel to the flow direction, the $\mathrm{Nu}$ and $h$ is observed to be 1.45 and $42.9 \mathrm{~W} /\left(\mathrm{m}^{2} \cdot \mathrm{K}\right)$, respectively. The case with $\theta=45^{\circ}$, yields the maximum $h$ with $44.22 \mathrm{~W} /\left(\mathrm{m}^{2} \cdot \mathrm{K}\right)$. However, due to almost equal strength of convection to diffusion, the systems with $\theta=45^{\circ}$ and $60^{\circ}$ yields almost equal value of average $\mathrm{Nu}$.

The relative orientation of the fin with respect to the incoming flow direction is also having effect on the flow losses. The effect of change of angle $\theta$ is

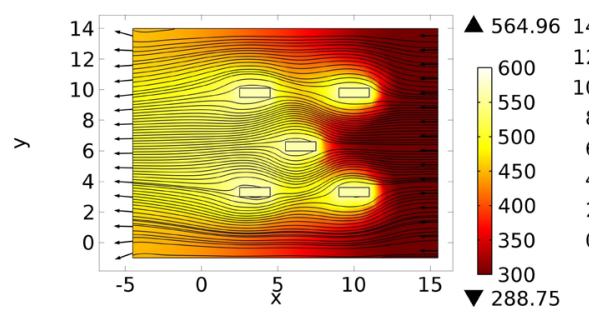

a)

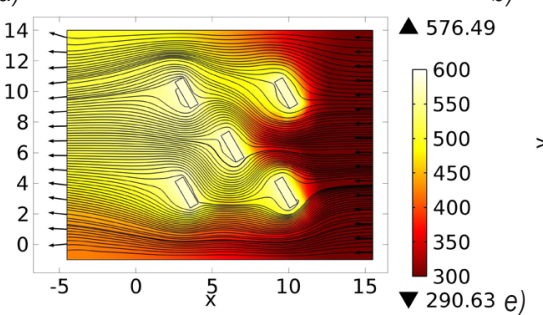

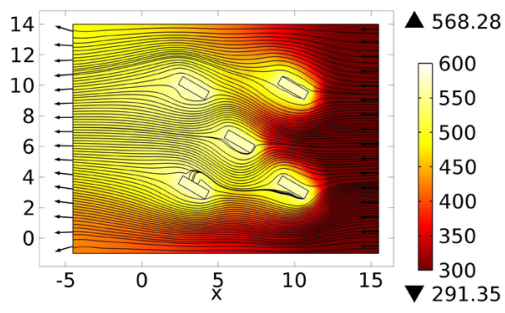

b)

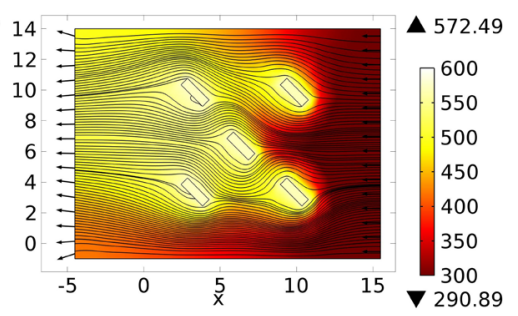

c)

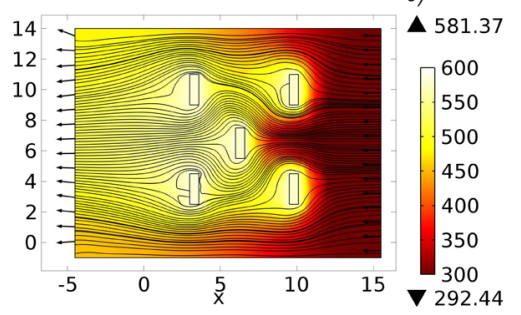

Fig. 7. Velocity streamline, direction and surface temperature $[\mathrm{K}]$ variation in staggered arrangement of fins at $z=6 \mathrm{~mm}$, with $\theta=$ a) $0^{\circ}$, b) $30^{\circ}$, c) $45^{\circ}$, d) $60^{\circ}$, e) $90^{\circ}$ 


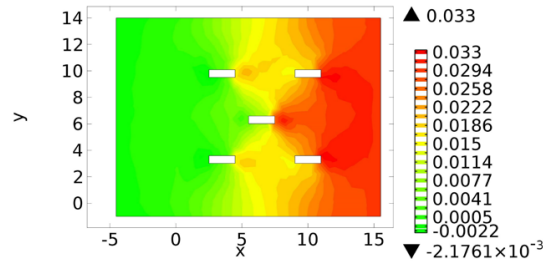

a)

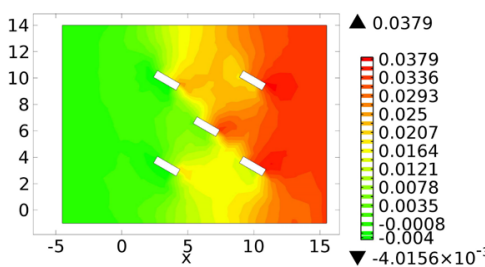

b)

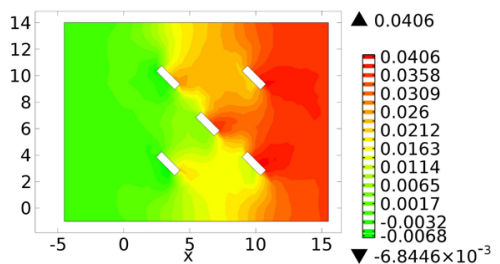

C)

d)
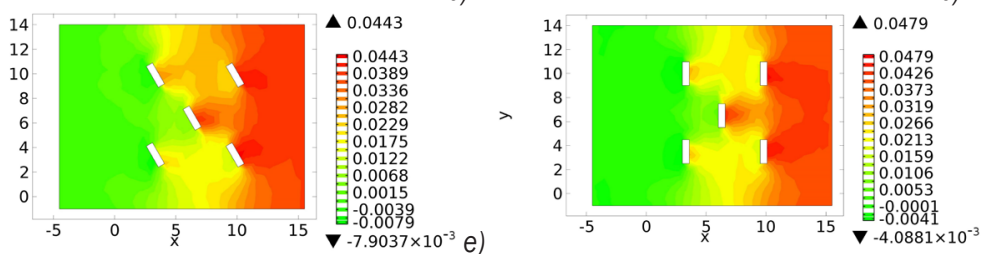

Fig. 8. Contour profile of pressure $[\mathrm{Pa}]$ in staggered arrangement of fins at $z=6 \mathrm{~mm}$ with $\theta=$ a) $0^{\circ}$; b) $30^{\circ}$; c) $45^{\circ}$; d) $60^{\circ}$; and e) $90^{\circ}$

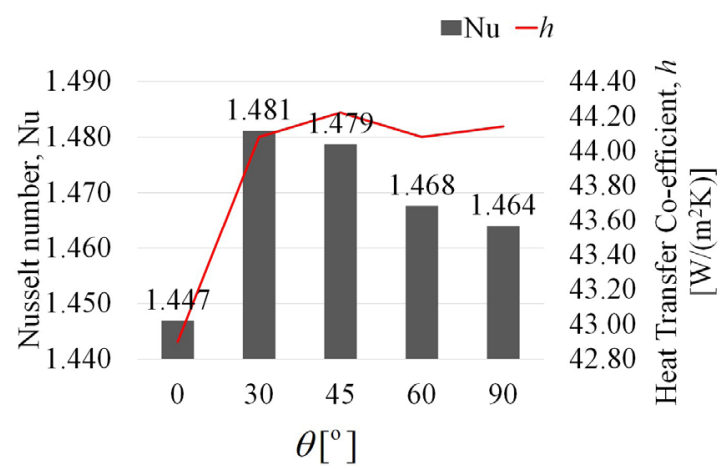

Fig. 9. Variation of $\mathrm{Nu}$ and $h$ for values of angle $\theta$ of triangular fins arranged in 2-1-2 staggered arrangement

observed in the variation of $C_{f}$ and $C_{p}$. Fig. 10 show the effect of $\theta$ on $C_{f}$ and $C_{p}$ for staggered arrangement of triangular fins with 2-1-2 configuration. A change in the angle of attack of the flow on the triangular fin leads to change in the formation of circulation zones downstream of the fin assembly. Fig. 11 represents the contours of $y$-component of velocity in $y z$ - plane immediately after the fin assembly, at $x=0$. It has been found that the section of the flow show two different orientation of the circular motion. The velocity $v$ in positive $y$ direction is marked in red and the one with blue color is observed to be in the negative $y$-direction. Upon comparison, it has been found that a staggered arrangement of triangular pin fin oriented in $0^{\circ}$ and $90^{\circ}$ yield two distinct vortices (Figs. 11a and e). However, the maximum velocity of the circulation zone is observed more in case of $90^{\circ}$ $(0.0391 \mathrm{~m} / \mathrm{s})$, compared to $0^{\circ}(0.0314 \mathrm{~m} / \mathrm{s})$. A fin with $0^{\circ}$ orientation, leads to lesser resistance in the flow compared to $90^{\circ}$. Therefore, the case with $\theta=0^{\circ}$ yield a minimum and lesser value of $C_{f}$ and $C_{p}$ compared to $\theta=90^{\circ}$ (Fig. 10). Now, when observing the cases with $0^{\circ}<\theta<90^{\circ}$, it has been found that the orientation of the fins leads to formation of four distinct vortices, making it to behave like a vortex generator. A fin at $\theta=$ $60^{\circ}$ yields vortices with maximum strength of the core $(0.0449 \mathrm{~m} / \mathrm{s}$ and $-0.0408 \mathrm{~m} / \mathrm{s})$. This leads to maximum values of $C_{f}$ and $C_{p}$ for $\theta=60^{\circ}$. It has been found that a fin placed at $30^{\circ}, 45^{\circ}, 60^{\circ}$, and $90^{\circ}$ produces 25
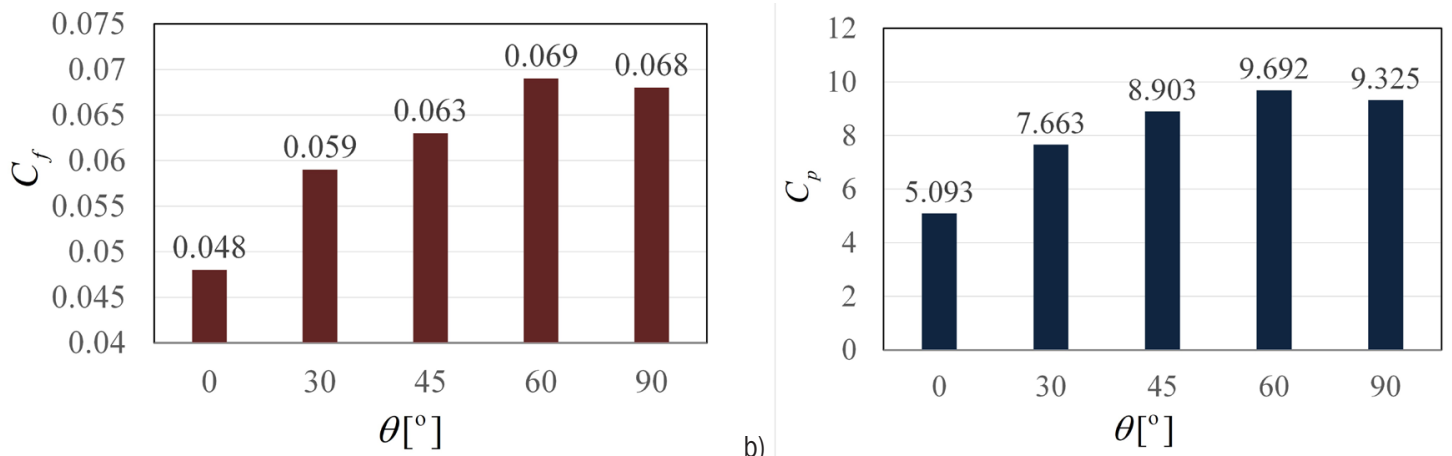

Fig. 10. Variation of a) $C_{f}$ and b) $C_{p}$ in staggered arrangement of fins with $\theta=0^{\circ}, 30^{\circ}, 45^{\circ}, 60^{\circ}$, and $90^{\circ}$ 

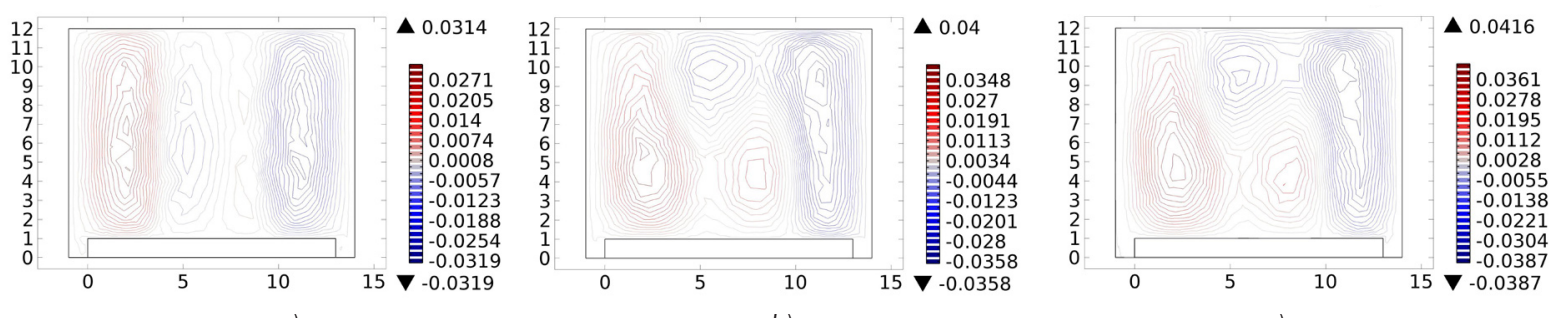

b)

c)
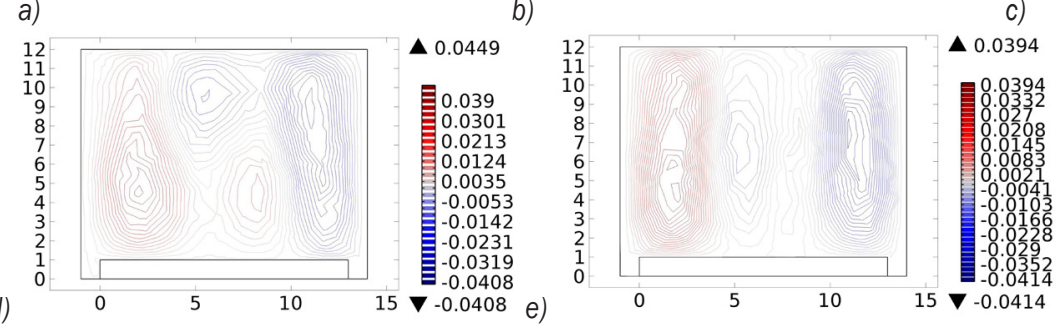

Fig. 11. Contour profile of $y$-component of velocity $v[\mathrm{~m} / \mathrm{s}]$ in staggered arrangement of fins in a plane at $x=0$, with $\theta=a), 0^{\circ}$, b) $30^{\circ}$, c) $45^{\circ}$, d) $60^{\circ}$, e) $90^{\circ}$

$\%, 32.5 \%, 44.8 \%$ and $42.7 \%$, respectively, more frictional losses in the flow compared to the case with $0^{\circ}$. On the other hand, the same set of fins at different angles produces $50.4 \%, 74.8 \%, 90.3 \%$ and $83 \%$ more pressure losses in the domain compared to the fin system parallel to the flow, i.e., $0^{\circ}$.

\subsection{Number of Fins}

With the understanding of heat transfer process in different arrangements of the fins, next the study has been extended to observe the effect of number of fins in the system. Four different cases with staggered arrangement of fins are considered with 2-1-2 (5 fins), 3-2-3 (8 fins), 4-3-4 (11 fins) and 5-4-5 (14 fins) staggered arrangement. The fins are place at angle $\theta$ $=0^{\circ}$ with the flow direction. A schematic diagram of the same is shown in Fig. 12. To maintain uniformity, the volume of all the fins and the aspect ratio (altitude: base) of individual fin is maintained the same as the earlier cases i.e. 2.5. Table 2 shows the results obtained from the numerical analysis for same boundary and thermal load conditions. It has been observed that as the numbers of fins are increased, the wetted surface area of the fins also increases, although the volume is remaining constant. However, the characteristic length of the fins decreases with increase in the number of fins. This affects the value of $\mathrm{Nu}$ and $h$. As the number of fins increases the $\mathrm{Nu}$ and the $h$ decreases.

Fig. 13 show variation of $C_{f}$ and $C_{p}$ for various configurations. As the number of fins increases, the wetted surface area of the domain increases. The increment in the surface area leads to more amount of shear stress experienced by the fin system. Hence, as the number of fins increases, the value of $C_{f}$ also increases (Fig. 13a). However, the variation of $C_{p}$ depicts a different scenario. As one moves from staggered 2-1-2 configuration to 3-2-3 configurations, the wetted surface area increases along with differential pressure. However, the relative rate of increment of pressure drop is found more than the increment in the wetted surface area in case of 2-1- a)

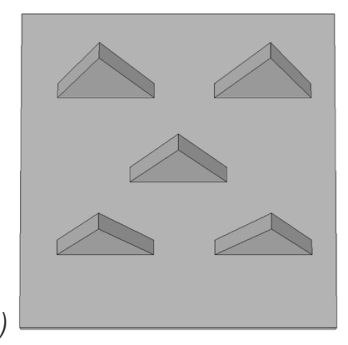

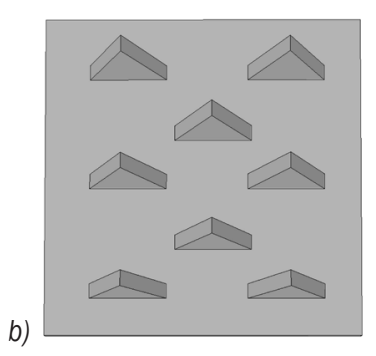
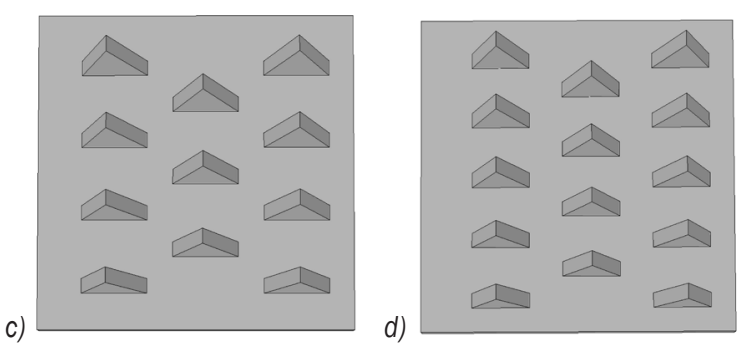

Fig. 12. Schematic diagram of staggered arrangement of fins placed parallel to the flow direction with;

a) $2-1-2$; b) 3-2-3; c) 4-3-4; d) 5-4-5 configuration 
2 configuration compared to 3-2-3 configurations. Hence, an increment in $C_{p}$ is observed. As one move from 3-2-3 to 4-3-4 configuration, the ratio of pressure drop with respect to dynamic pressure is found to reduce and hence, the value of $C_{p}$ decreases further.

Table 2. Comparison of values of $\mathrm{Nu}$ and $h$ for various numbers of fins placed parallel to the flow direction with staggered arrangements

\begin{tabular}{cccccc}
\hline Cases & $\begin{array}{c}\text { Number } \\
\text { of fins }\end{array}$ & $\mathrm{Nu}$ & $\begin{array}{c}h \\
{\left[\mathrm{~W} /\left(\mathrm{m}^{2} \cdot \mathrm{K}\right)\right]}\end{array}$ & $\begin{array}{c}\text { Wetted } \\
\text { surface } \\
\text { area [mm²] }\end{array}$ & $\begin{array}{c}\text { Characteristic } \\
\text { length [mm] }\end{array}$ \\
\hline $2-1-2$ & 5 & 1.48 & 44.22 & 469.66 & 1.95 \\
\hline $3-2-3$ & 8 & 1.87 & 59.24 & 482.69 & 1.90 \\
\hline $4-3-4$ & 11 & 1.26 & 41.97 & 493.45 & 1.85 \\
\hline $5-4-5$ & 14 & 1.11 & 39.06 & 502.73 & 1.82 \\
\hline
\end{tabular}

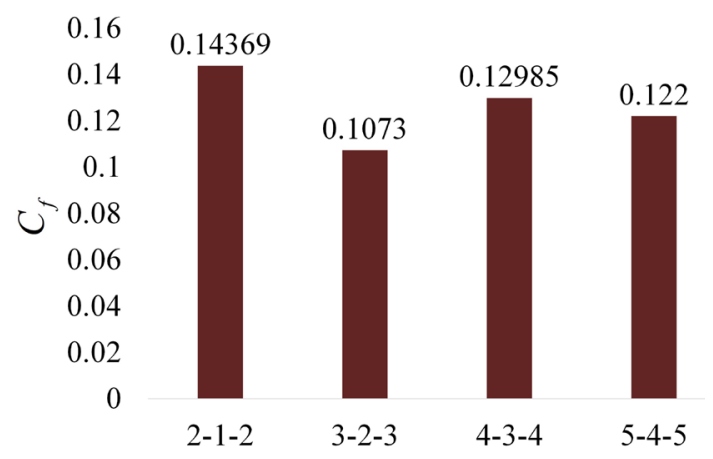

a)

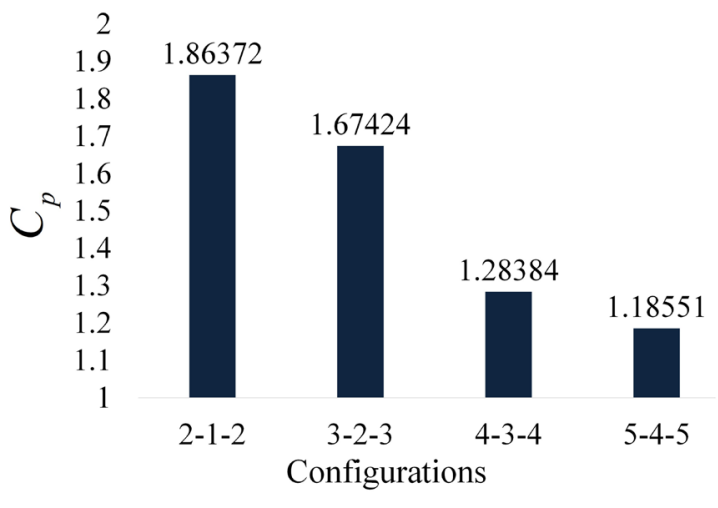

Fig. 13. Variation of a) $C_{f}$; and b) $C_{p}$ in staggered arrangement of fins of various configuration

\section{CONCLUSIONS}

The present work reported thermal analysis of triangular shaped fins for different parametric conditions. The problem is analyzed numerically using an FEM solver. The numerical model, boundary conditions and the solver is validated for cylindrical fins of staggered arrangement using the experimental data and empirical relationship proposed by Khan et al. [12]. The comparison shows an acceptable agreement. Further, the analysis is done on triangular shaped fins for a fixed value of inlet Re. A comparison of the inline and staggered arrangement is shown and is observed that the staggered arrangement gives a better heat transfer rate from a solid surface to the fluid. Fins with staggered arrangement and placed parallel to the incoming flow is found to yield an enhanced value of $\mathrm{Nu}$ and $h$. It has also been observed, as the number of fins increases the heat transfer rate deteriorate due to reduced value of characteristic length of the fins geometries. A change in configuration of the fin system affects the losses in the flow domain. A staggered arrangement as considered in the current study yield a lower value of $C_{p}$ and $C_{f}$. Fins placed parallel to the flow direction are more streamlined and found to have minimum pressure loss and frictional loss. Therefore, a triangular fin system with staggered arrangement placed parallel to the flow direction may be preferred from effective thermal and flow behavior point of view. In the present study, the effect of increment of number of fins is found to affect the heat transfer and the fluid flow physics. However, it is difficult to predict the effect of number of fins on $C_{p}$ and $C_{f}$, for staggered arrangement of fin system.

\section{NOMENCLATURES}

\begin{tabular}{|c|c|}
\hline$A$ & area, $\left[\mathrm{m}^{2}\right]$ \\
\hline$c_{p}$ & specific heat, $[\mathrm{J} /(\mathrm{kg} \cdot \mathrm{K})]$ \\
\hline$C_{p}^{P}$ & coefficient of friction, [-] \\
\hline$C_{f}$ & coefficient of pressure, $[-]$ \\
\hline$C_{1}$ & arbitrary constant, $[-]$ \\
\hline$D$ & diameter, $[\mathrm{mm}]$ or $[\mathrm{m}]$ \\
\hline $\mathrm{H}$ & height, $[\mathrm{mm}]$ or $[\mathrm{m}]$ \\
\hline$h$ & heat transfer coefficient, $\left[\mathrm{W} /\left(\mathrm{m}^{2} \cdot \mathrm{K}\right)\right.$ \\
\hline$k$ & thermal conductivity, $[\mathrm{W} /(\mathrm{m} \cdot \mathrm{K})]$ \\
\hline$l_{2} \mathrm{~L}$ & length, $[\mathrm{mm}]$ or $[\mathrm{m}]$ \\
\hline$\hat{n}$ & unit normal vector, [-] \\
\hline $\mathrm{Nu}$ & average Nusselt number, [-] \\
\hline$p$ & pressure, $[\mathrm{Pa}]$ or $\left[\mathrm{N} / \mathrm{m}^{2}\right]$ \\
\hline$P_{o}$ & atmospheric pressure, $[\mathrm{Pa}]$ \\
\hline $\operatorname{Pr}$ & Prandtl number, [-] \\
\hline$Q_{s}$ & heat supplied, [W] \\
\hline $\mathrm{Re}$ & Reynolds number, [-] \\
\hline$S$ & pitch, $[\mathrm{mm}]$ or $[\mathrm{m}]$ \\
\hline$t$ & time, $[\mathrm{s}]$ \\
\hline $\mathrm{T}$ & temperature, $[\mathrm{K}]$ \\
\hline$\vec{u}_{y}$ & $y$ - component of velocity, $[\mathrm{m} / \mathrm{s}]$ \\
\hline$U, \vec{V}$ & total velocity, $[\mathrm{m} / \mathrm{s}]$ \\
\hline$x, y$ & co-ordinate axes, [-] \\
\hline
\end{tabular}


Greek Symbols

$v \quad$ dynamic viscosity, $\left[\mathrm{N} \cdot \mathrm{s} / \mathrm{m}^{2}\right]$

$\rho$ density, $\left[\mathrm{kg} / \mathrm{m}^{3}\right]$

$\theta \quad$ inclination in degree, $\left[{ }^{\circ}\right]$

Subscripts

b base plate

$D \quad$ diameter or diagonal

$f \quad$ fluid

$L \quad$ longitudinal

max maximum

$T \quad$ transverse

w wall

\section{REFERENCES}

[1] Axtmann, M., Poser, R., von Wolferdorf, J., Bouchez, B. (2016). End wall heat transfer and pressure loss measurements in staggered arrays of adiabatic pin fins. Applied Thermal Engineering, vol. 103, p. 1048-1056, D0l:10.1016/j. applthermaleng.2016.04.066.

[2] Şara, 0. N. (2003). Performance analysis of rectangular ducts with staggered square pin fins. Energy Conversion and Management, vol. 44, no. 11, p. 1787-1803, Dol:10.1016/ S0196-8904(02)00185-1.

[3] Jeng, T.-M., Tzeng, S.-C. (2007). Pressure drop and heat transfer of square pin-fin arrays in in-line and staggered arrangements. International Journal of Heat and Mass Transfer, vol. 50, no. 11-12, p. 2364-2375, Dol:10.1016/j. ijheatmasstransfer.2006.10.028.

[4] Metzger, D. E., Berry, R. A., Bronson, J. P. (2009). Developing heat transfer in rectangular ducts with staggered arrays of short pin fins. Journal of Heat Transfer, vol. 104, no. 4, p. 700706, Dol:10.1115/1.3245188.

[5] Agrawal, S., Terrence, W.S., North, M., Bissell, D., Cui, T. (2015). Heat transfer augmentation of a channel flow by active agitation and surface mounted cylindrical pin fins. International Journal of Heat and Mass Transfer, vol. 87, p. 557-567, DOl:10.1016/j.jijheatmasstransfer.2015.04.036.

[6] Park, S.-J., Jang, D., Yook, S.J., Lee, K.-S. (2015). Optimization of a staggered pin-fin for a radial heat sink under free convection. International Journal of Heat and Mass Transfer, vol. 87, p. 184-188, D0l:10.1016/j. ijheatmasstransfer.2015.04.036.

[7] Huang, C.-H., Liu, Y.-C., Ay, H. (2015). The design of optimum perforation diameters for pin fin array for heat transfer enhancement. International Journal of Heat and Mass Transfer, vol. 84, p. 752-765, D0l:10.1016/j. ijheatmasstransfer.2014.12.065.

[8] Sahin, B., Demir, A. (2008). Performance analysis of a heat exchanger having perforated square fins. Applied Thermal Engineering, vol. 28, no. 5-6, p. 621-632, D0l:10.1016/j. applthermaleng.2007.04.003.

[9] Abdoli, A., Jimenez, G., Dulikravich, G. S. (2015). Thermofluid analysis of micro pin-fin array cooling configurations for high heat fluxes with a hot spot. International Journal of Thermal Sciences, vol. 90, p. 290-297, D0l:10.1016/j. applthermaleng.2007.04.003.

[10] Joo, Y., Kim, S. J. (2015). Comparison of thermal performance between plate-fin and pin-fin heat sinks in natural convection. International Journal of Heat and Mass Transfer, vol. 83, p. 345-356, DOI:10.1016/j.jigheatmasstransfer.2014.12.023.

[11] McNeil, D. A., Raeisi, A. H., Kew, P. A., Hamed, R. S. (2014). An investigation into flow boiling heat transfer and pressure drop in a pin-finned heat sink. International Journal of Multiphase Flow, vol. 67, p. 65-84, D0l:10.1016/j. ijmultiphaseflow.2014.06.012.

[12] Khan, W. A., Culham, J. R., Yovanovich, M. M. (2005). Modelling of cylindrical pin fin heat sinks for electronic packaging. Proceedings of 21st IEEE Semiconductor Thermal Measurement and Management (SEMI-THERM) Symposium, San Jose. 